\title{
A green synthesis of copper oxide nanoparticles by mechanochemical method
}

\author{
Azadeh Tadjarodi* and Reza Roshani
}

Research Laboratory of Inorganic Materials Synthesis, Department of Chemistry, Iran University of Science and Technology, Narmak, Tehran, 1684613114, Iran

\begin{tabular}{|c|c|}
\hline CHRON I C LE & A B S T RACT \\
\hline $\begin{array}{l}\text { Article history: } \\
\text { Received January 22, } 2014 \\
\text { Received in revised form } \\
\text { February } 02,2014 \\
\text { Accepted } 28 \text { May } 2014 \\
\text { Available online } \\
5 \text { June } 2014\end{array}$ & $\begin{array}{l}\text { Copper oxide nanoparticles were successfully synthesized by mechanochemical reaction, which } \\
\text { is a green, low cost, solvent free, rapid method and followed by calcining treatment. Copper } \\
\text { acetate monohydrate and urea were used as reagents and the resulted precursor was calcined at } \\
500{ }^{\circ} \mathrm{C} \text { for } 2 \mathrm{~h} \text { in air. The scanning electron microscopy (SEM) revealed the formation of } \\
\text { nanoparticles with an average size of about } 86 \mathrm{~nm} \text {. The Fourier transform infrared (FT-IR) } \\
\text { spectrum and X-ray powder diffraction (XRD) pattern of the product confirmed all of }\end{array}$ \\
\hline $\begin{array}{l}\text { Keywords: } \\
\text { Copper oxide }\end{array}$ & $\begin{array}{l}\text { reflections can be indexed to pure phase of } \mathrm{CuO} \text { with a monoclinic crystal system. The diffuse } \\
\text { reflectance spectrum (DRS) showed a band gap of } 1.7 \mathrm{eV} \text {. }\end{array}$ \\
\hline
\end{tabular}

Green synthesis

Nanoparticles

Mechanochemical

Semiconducto

\section{Introduction}

Nanostructured materials have stimulated intensive research interest in the recent years due to their unique properties and the potential applications in photonic and nanoelectronics, which are dependent on size of particles ${ }^{1}$. Cupric oxide, $\mathrm{CuO}$, is an important $p$-type semiconductor metal oxide with a band gap of $1.0-4.5 \mathrm{eV}^{2,3}$, which is widely used in nano systems such as high temperature superconductors ${ }^{4}$, magnetic storage media ${ }^{1,5}$, solar cells ${ }^{1,3-9}$, hydrogen storage materials ${ }^{7}$, batteries ${ }^{1,2,8}$, gas sensors ${ }^{1-10}$, catalysis $^{2-7,9,10}$. Up to date, $\mathrm{CuO}$ with different morphologies such as nanobelt ${ }^{1,8}$, nanospindle ${ }^{2}$, nanoring ${ }^{2,4}$, nanorod ${ }^{1,4,6}$, nanospherical ${ }^{8}$, nanoribbon $^{2,4,9}$, nanoparticle ${ }^{4,8}$, nanoleaf ${ }^{2,11}$, nanotube nand $^{4,9,11}$ and nanowire $2,4,9,12,13$ has been successfully synthesized by various techniques, including thermal decomposition ${ }^{1}$, chemical vapor deposition $^{1,2}$, microwave-hydrothermal ${ }^{7}$, sonochemical ${ }^{1,2}$, solvothermal, hydrothermal process ${ }^{1,2,12}$, sol-gel $^{2}$, thermal oxidation ${ }^{7,8,9,12,13}$ methods. One of the approaches to synthesize metal oxide nanostructures is the ball milling or mechanochemical method ${ }^{14-16}$. In fact, mechanical milling (MM) is an effective, useful, low cost and a simple technique, which is used to synthesize numerous

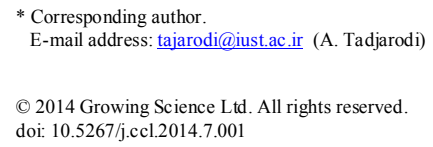


materials including solid solutions, quasicrystalline, nanocrystalline and crystalline materials. This process was developed by Benjamin and his co-workers in 1960s as milling mixing for the first time. Then Mac-Queen described its patent application ${ }^{17}$. In this work, we synthesized nanoparticles of $\mathrm{CuO}$ with band gap of $1.7 \mathrm{eV}$ by utilizing mechanochemical reaction and then calcination procedure. The obtained precursor was studied by TGA, CHN, ICP and FT-IR spectroscopy. The final product was characterized by FT-IR spectroscopy, XRD and SEM techniques.

\section{Results and Discussion}

\subsection{Structural and morphological study}

The composition changes associated with the calcination process were observed by thermal analysis. TGA curve shown in Fig. 1 indicates a several-steps pattern of weight loss in the temperature range $80-430{ }^{\circ} \mathrm{C}$. The first weight loss of $2 \%$ occurred below the temperature of 100 ${ }^{\circ} \mathrm{C}$ could be attributed to the release of surface adsorbed water. Thenceforth weight loss of $69 \%$ observed between 125 and $430{ }^{\circ} \mathrm{C}$ may be related to the decomposition of organic groups in the precursor. These composition changes are completed at $430{ }^{\circ} \mathrm{C}$.

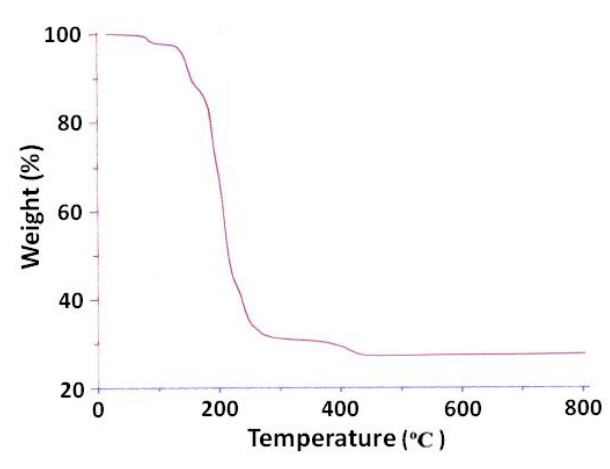

Fig. 1. TGA curve of the precursor

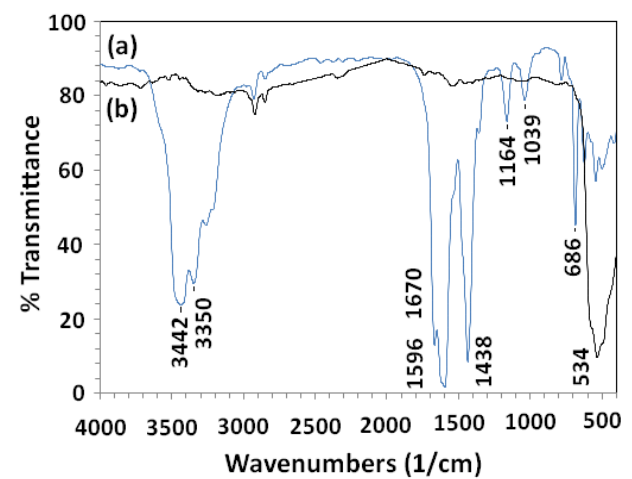

Fig. 2. FT-IR spectra of (a) the precursor and (b) the product after heating at $500{ }^{\circ} \mathrm{C}$ for $2 \mathrm{~h}$ in air

Fig. 2 shows the FT-IR spectra of (a) the precursor and (b) the product after heating at $500{ }^{\circ} \mathrm{C}$ for 2 $\mathrm{h}$ in air. The broad double bands at 3442 and $3350 \mathrm{~cm}^{-1}$ in Fig. 2-a are related to the $\mathrm{N}-\mathrm{H}$ anti symmetrical and symmetrical stretching vibrations, respectively, which are in a close agreement with vibrations of the $\mathrm{NH}_{2}$ group. The overlapping $\mathrm{O}-\mathrm{H}$ stretching band of $\mathrm{H}_{2} \mathrm{O}$ molecules with the $\mathrm{NH}_{2}$ vibrations led to broaden these bands. The strong peaks at 1670 and $1596 \mathrm{~cm}^{-1}$ are assigned to the stretching vibration of the carbonyl groups. In fact, the frequency of the $\mathrm{C}=\mathrm{O}$ vibrations decreases by the ligand coordination effect of oxygen atom of the amide and acetate groups. The peaks at 1438 $\mathrm{cm}^{-1}$ belong to the antisymmetrical bending vibrations of the methyl groups. Also, the observed peaks at $686 \mathrm{~cm}^{-1}$ are related to the $\mathrm{C}-\mathrm{O}$ bending vibrations ${ }^{18,19}$. As a result of heating, the organic section of precursor was removed and the specified broad band at around $534 \mathrm{~cm}^{-1}$ belongs to the $\mathrm{Cu}-\mathrm{O}$ vibration (Fig. 2-b) ${ }^{20}$.

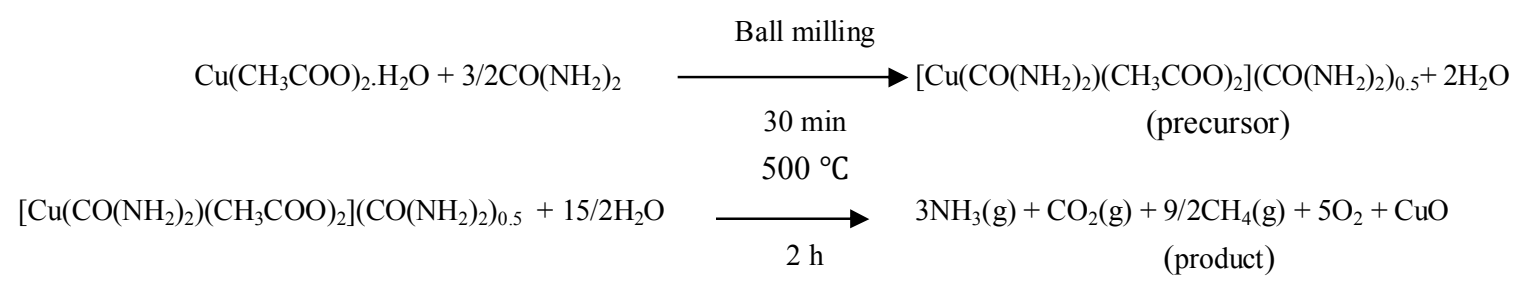

Scheme 1. The proposed mechanism for the formation of the product 
In addition to FT-IR data, we used elemental analysis, $\mathrm{CHN}$ and ICP, in order to confirm the formation of precursor. Anal. Calcd. for : $\left(\mathrm{CuC}_{5.5} \mathrm{H}_{12} \mathrm{~N}_{3} \mathrm{O}_{5.5}\right)$ : C, 24.30: $\mathrm{H}, 4.42: \mathrm{N}, 15.46: \mathrm{Cu}, 23.39$. Found: C, 23.98: H, 4.44: N, 15.17: $\mathrm{Cu}: 23.33$ (\%). These data confirm the suggested molecular formula $\left[\mathrm{Cu}\left(\mathrm{CO}\left(\mathrm{NH}_{2}\right)_{2}\right)\left(\mathrm{CH}_{3} \mathrm{COO}\right)_{2}\right]\left(\mathrm{CO}\left(\mathrm{NH}_{2}\right)_{2}\right)_{0.5}$ for the precursor.

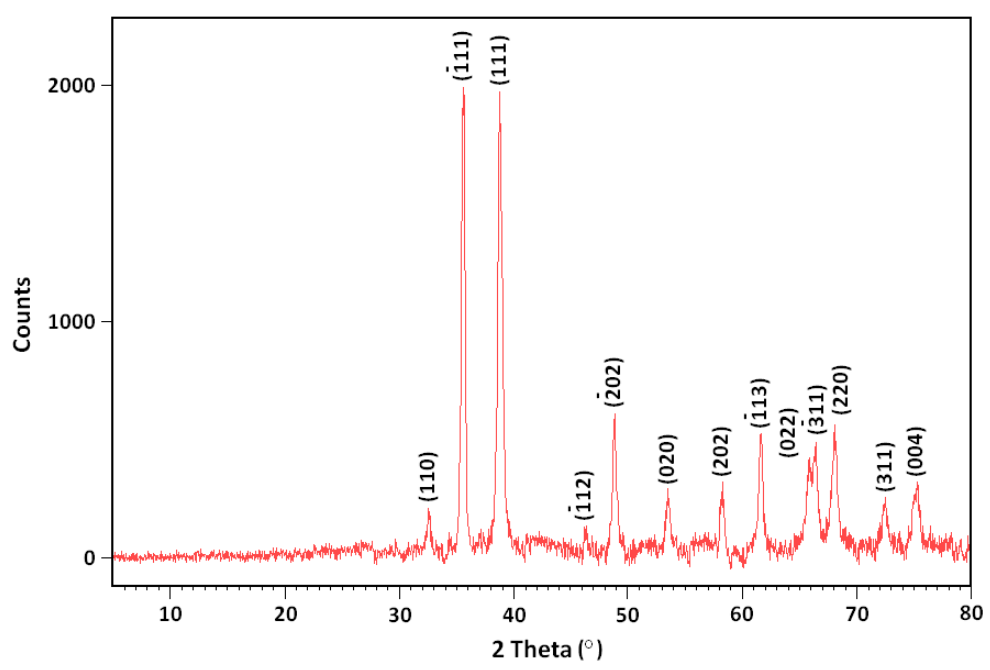

Fig. 3. XRD pattern of the product

According to XRD pattern, as shown in Fig. 3, the diffraction peaks could be indexed to a monoclinic phase of $\mathrm{CuO}$ (S.G.: $\mathrm{C} 2 / c$ ) and the lattice parameters were obtained $a=4.684, \quad b=$ 3.425 , and $c=5.129$, and $\beta=99.47^{\circ}$ (JCPDS 05-0661). The diffraction peaks at $2 \theta$ values of $32.52^{\circ}$, $35.55^{\circ}, 38.73^{\circ}, 46.31^{\circ}, 48.76^{\circ}, 53.41^{\circ}, 58.32^{\circ}, 61.57^{\circ}, 65.81^{\circ}, 66.23^{\circ}, 68.14^{\circ}, 72.42^{\circ}$ and $75.02^{\circ}$

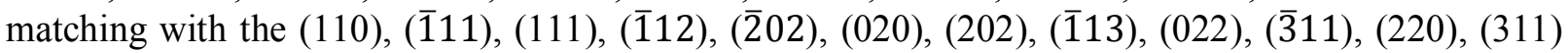
and (004) planes of monoclinic $\mathrm{CuO}$ confirmed the formation of $\mathrm{CuO}$ compound with excellent crystallinity and no other peaks for impurities. The peak intensities and widths clearly indicate that the sample was highly crystalline in nature.

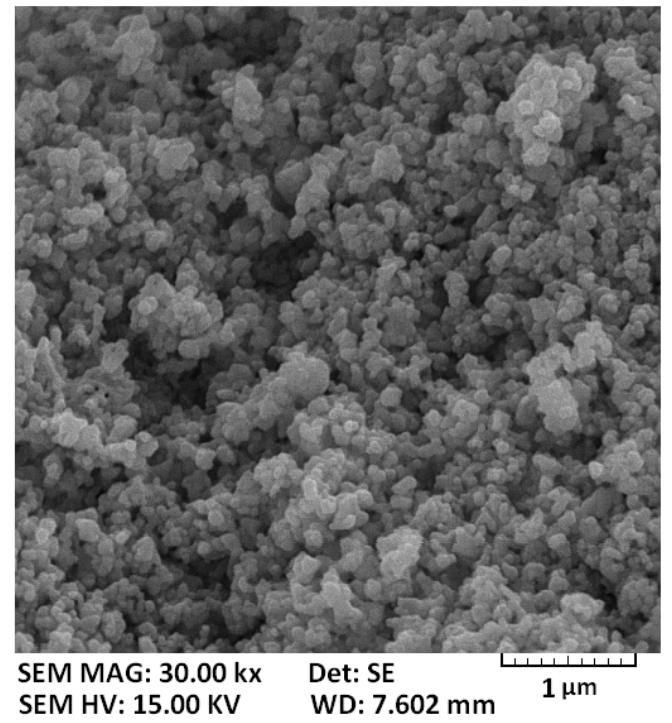

Fig. 4. SEM images of $\mathrm{CuO}$ nanoparticles 
The morphology and size product were investigated by SEM. Fig. 4 reveals the SEM image of $\mathrm{CuO}$ nanoparticles. This image shows the nanoparticles with an average size of about $86 \mathrm{~nm}$.

\subsection{The optical property}

The optical absorption of the $\mathrm{CuO}$ nanoparticles was investigated in the wavelength range of $190-$ $800 \mathrm{~nm}$. Fig. 5-a illustrates the DRS of $\mathrm{CuO}$ nanoparticles. The absorption band gap $\mathrm{E}_{\mathrm{g}}$, can be determined by the Eq. $(1)^{21}$.

$(\alpha \mathrm{h} v)^{\mathrm{n}}=\beta\left(\mathrm{h} v-\mathrm{E}_{\mathrm{g}}\right)$

where, $h v$ is the photo energy, $\alpha$ is the absorption coefficient, $\beta$ is a constant relative to the material and $\mathrm{n}$ is either 2 for a direct transition or $1 / 2$ for an indirect transition. We have plotted $(\alpha \mathrm{h} v)^{2}$ versus $\mathrm{h} v$ curves in order to determine the band gap. According to Fig. 5-b, the band gap for $\mathrm{CuO}$ nanoparticles was found to be $1.7 \mathrm{eV}$. It is expected that these $\mathrm{CuO}$ nanoparticles can be used as photocatalyst. The observed differences between the calculated band gap and the reported values in the literatures arise from size and density of $\mathrm{CuO}$ nanoparticles.

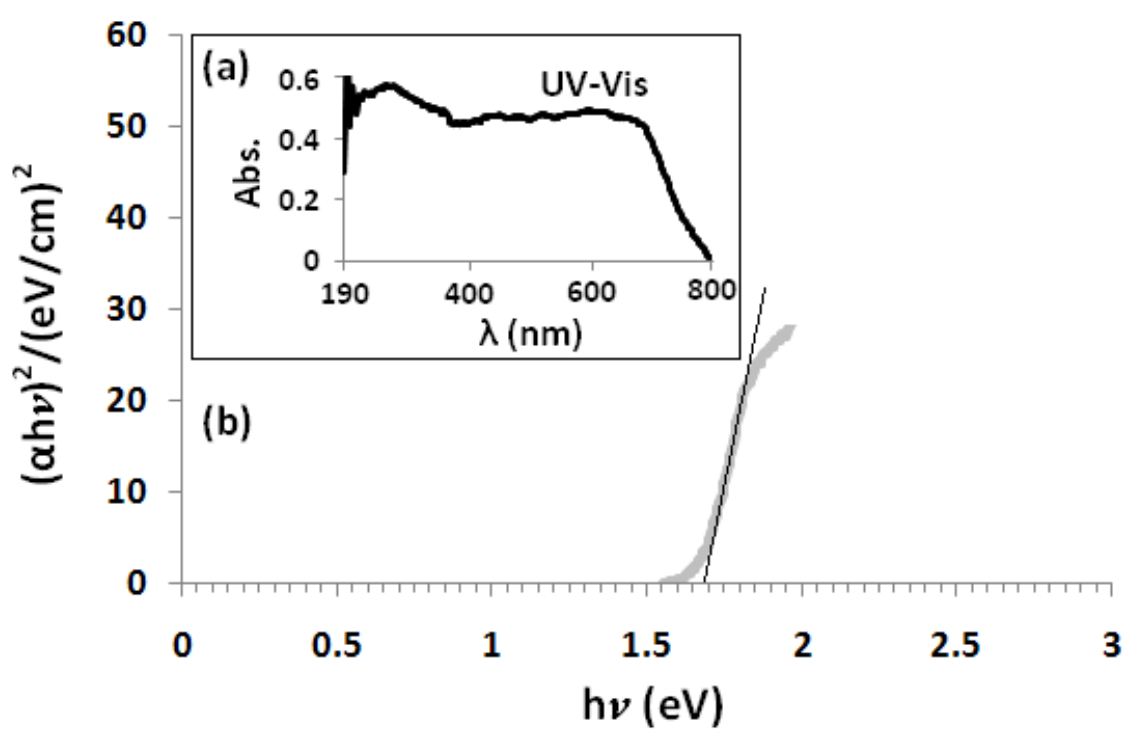

Fig. 5. (a) The Uv-vis diffuse reflectance spectrum in the inset and (b) the plot $(\alpha h v)^{2}$ versus $h v$ curves for $\mathrm{CuO}$ nanoparticles

\section{Conclusions}

In summary, the nanoparticles of copper oxide with an average size of about $86 \mathrm{~nm}$ and band gap of $1.7 \mathrm{eV}$ were prepared by mechanochemical process followed by calcining treatment. The FT-IR spectrum and XRD pattern of the product confirms all of reflections can be indexed to pure phase of $\mathrm{CuO}$ with a monoclinic crystal system. Actually, mechanochemical method is performed in solid state and does not involve any organic solvents, it can be applicable for the preparation of various nanomaterials in industry because of simple, low cost and being environmentally. It is expected that these $\mathrm{CuO}$ nanoparticles can be used as photocatalyst. 


\section{Acknowledgements}

The financial support of this work, by Iran University of Science and Technology and Iranian Nanotechnology Initiative, is gratefully acknowledged.

\section{Experimental}

\subsection{Materials and methods}

All chemicals were purchased from Merck Co. and used without further purification. Double distilled water was used in all experiments.

The powder X-ray diffraction (XRD) analysis was done with a PHILIPS PW 1800 diffractometer with monochromatized $\mathrm{Cu} \mathrm{K} \alpha$ radiation $(\lambda=1.542 \AA)$. Fourier transform infrared (FT-IR) spectra were recorded on a Shimadzu-8400S spectrometer in the range of $400-4000 \mathrm{~cm}^{-1}$ using KBr pellets. Scanning electron microscopy (SEM) obtained on a VEGA $\backslash T E S C A N$ with gold coating. Thermogravimetric analysis (TGA) measurement was carried on a TA Instruments 931 apparatus with a heating rate of $10{ }^{\circ} \mathrm{C} \mathrm{min}^{-1}$ under nitrogen flow. Elemental analysis was performed by utilizing a Perkin Elmer (model 2400, series 2) CHN microanalyser. The content analyses of copper were performed by the VARIAN VISTA-PRO ICP-OES simultaneous. The diffuse reflectance spectrum (DRS) was recorded on a Shimadzu- MPC - 2200 spectrophotometer.

\subsection{General procedure}

$\mathrm{Cu}\left(\mathrm{CH}_{3} \mathrm{COO}\right)_{2} \cdot \mathrm{H}_{2} \mathrm{O}$ and $\mathrm{CO}\left(\mathrm{NH}_{2}\right)_{2}$ were milled together with a molar ratio of 2:3 and then were put in a stainless steel $10 \mathrm{~mL}$ vial containing two small balls of $10 \mathrm{~mm}$ diameter by utilizing a mass ratio of 8:1 ball-to-powder. In fact, milling was carried out with Mixer Mill (Retsch MM-400) apparatus at $1800 \mathrm{rpm}(30 \mathrm{~Hz})$ for $30 \mathrm{~min}$ at room temperature. The resultant bluish substance as precursor was calcinated at $500{ }^{\circ} \mathrm{C}$ for $2 \mathrm{~h}$ in a furnace. The progress of reaction was monitored by TLC and M.P.

\section{References}

1. Dodoo-Arhin D., Leoni M., Scardi P. (2012). Microemulsion synthesis of copper oxide nanorodlike structures. Mol. Cryst. Liq. Cryst., 555, 17-31.

2. Chen G., Zhou H., Ma W., Zhang D., Qiu G., Liu X. (2011). Microwave-assisted synthesis and electrochemical properties of urchin-like CuO micro-crystals. Solid State Sci., 13, 2137-2141.

3. Rahnama A., Gharagozlou M. (2012). Preparation and properties of semiconductor $\mathrm{CuO}$ nanoparticles via a simple precipitation method at different reaction temperatures. Opt. Quant. Electron., 44, 313-322.

4. Yu Y., Zhang J. (2009). Solution phase synthesis of rose like CuO. Mater. Lett., 63, 1840-1843.

5. Jia Z., Yue L., Zheng Y., Xu Z. (2008). The convenient preparation of porous $\mathrm{CuO}$ via copper oxalate precursor. Mater. Res. Bull., 43, 2434-2440.

6. Sabbaghan M., Mirzaei Behbahani B. (2014). Synthesis and optical properties of $\mathrm{CuO}$ nanostructures in imidazolium-based ionic liquids. Mater. Lett., 117, 28-30.

7. Safarifard V., Morsali A. (2012). Sonochemical syntheses of a nano-sized copper (II) supramolecule as a precursor for the synthesis of copper(II) oxide nanoparticles. Ultrason. Sonochem., 19, 823-829.

8. Wu R., Ma Z., Gu Z., Yang Y. (2010). Preparation and characterization of CuO nanoparticles with different morphology through a simple quick-precipitation method in DMAC-water mixed solvent. J. Alloy Compd., 504, 45-49. 
9. Liu L., Hong K., Hu T., Xu M. (2012). Synthesis of aligned copper oxide nanorod arrays by a seed mediated hydrothermal method. J. Alloy Compd., 511, 195-197.

10. Zhu J., Bi H., Wang Y., Wang X., Yang X., Lu L. (2007). Synthesis of flower-like CuO nanostructures via a simple hydrolysis route. Mater. Lett., 61, 5236-5238.

11. Zheng L., Liu X. (2007). Solution-phase synthesis of CuO hierarchical nanosheets at near-neutral $\mathrm{pH}$ and near-room temperature. Mater. Lett., 61, 2222-2226.

12. Hwan Ko Y., Nagaraju G., Hyun Lee S., Su Yu J. (2014). Facile preparation and optoelectronic properties of $\mathrm{CuO}$ nanowires for violet light sensing. Mater. Lett., 117, 217-220.

13. Kuan Lee S., Hsing Tuan W. (2014). Scalable process to produce $\mathrm{CuO}$ nanowires and their formation mechanism. Mater. Lett., 117, 101-103.

14. Ding C., Hong-yan L., Shu-ren X. (2012). One-step decomposition of basic carbonates into single-phase crystalline metallic oxides nanoparticle by ultrasonic wave-assisted ball milling technology. Ceram. Int. 38, 821-825.

15. Tadjarodi A., Imani M. (2011). Synthesis and characterization of $\mathrm{CdO}$ nanocrystalline structure by mechanochemical method. Mater. Lett., 65, 1025-1027.

16. Tadjarodi A., Imani M. (2011). A novel nanostructure of cadmium oxide synthesized by mechanochemical method. Mater. Res. Bull., 46, 1949-1954.

17. Suryanarayana C. (2001). Mechanical alloying and milling. Prog. Mater. Sci., 46, 1-184.

18. Nakamoto K. (2009). Infrared and Raman Spectra of Inorganic and Coordination Compounds, 6th ed., John Wiley \& Sons, Inc., Hoboken, New Jersey.

19. Pavia D.L.G.L., Kriz G.S., Vyvyan J.R. (2009) Introduction to Spectroscopy, 4th ed. Brooks/cole Cengage Learning, United State.

20. Cai Zhang Y., Yuan Tang J., Lin Wang G., Zhang M., Ya Hu X. (2006). Facile synthesis of submicron $\mathrm{Cu}_{2} \mathrm{O}$ and $\mathrm{CuO}$ crystallites from a solid metallorganic molecular precursor. J. Cryst. Growth, 294, 278-282.

21. Al-Gaashani R., Radiman S., Tabet N., Razak Daud A. (2011). Synthesis and optical properties of $\mathrm{CuO}$ nanostructures obtained via a novel thermal decomposition method. J. Alloy Compd., 509, 8761-8769. 